\title{
Towards a Better Investment of University Students in Light of the Twentieth Century Challenges
}

\author{
Ismael Al-Nabrawi ${ }^{1}$, Malek Jdaitawi ${ }^{1} \&$ Feras Talafha $^{1}$ \\ ${ }^{1}$ Preparatory Year and Supporting Studies, University of Dammam, Saudi Arabia \\ Correspondence: Ismael Al-Nabrawi, Self Development Department, University of Dammam, Saudi Arabia. Tel: \\ 966-554-378-640. E-mail: Imalnabrawi@uod.edu.sa
}

\author{
Received: January 22, 2015 Accepted: February 22, 2015 Online Published: May 28, 2015 \\ doi:10.5539/ies.v8n6p113 URL: http://dx.doi.org/10.5539/ies.v8n6p113
}

\begin{abstract}
Present study has been conducted with the purpose of impact of university skills training on students psycho-social and cognitive skills of males' students in preparatory year deanship in university of Dammam in 2014/2015. The present study is quasi-experimental pre-post-test design was used with control group. The study sample was 150 subjects and randomly assigned into experimental and control group. The experimental group was trained four days. Findings of ANOVA, MANOVA and MANCOVA showed that the training program was positively and significantly effect on self-confidence, self-assertiveness, tolerance of responsibility and problem solving. Furthermore, the results also showed that students had a significant difference on self-assertiveness and self-awareness based on their study track. Thus, a comprehensive training program is needed in the field of university life to help students adjust and success.
\end{abstract}

Keywords: training program, university life, psycho-social skills, cognitive skills

\section{Introduction}

The educational process is basically deemed among the top pillars of the development and progress of an individual in terms of the nation's development. On the basis of this notion, countries are focused on the educational process they provide as a kind of investment. This is evidenced in higher educational systems that are dedicated to the provision of fundamental requirements of learning-teaching process in its entirety with the belief that progress and development can only be realized through educational progress. In fact, universities are deemed to be the manufacturing entity that forms and generates potential leaders who are the sources of thought and the gauge that measures the progress of a nation. Successful university students are evidenced to be related with related variables. A thorough literature review reveals that the student's successes at the university are predicted at the onset of his university years via the examination of his characteristics. Based on this, Tinto (1998) indicated that a socially integrated student in his campus can easily succeed in studies and that college education impact on individual's factors reveals its important aspect.

In this context, the student's life skills, personal and social skills are very crucial and every student should be able to handle their personal issues and their issues with other relevant others in the community for effective decision making and action (Sahebalzamani, Moraveji, Farahani, \& Feizi, 2013). People generally go through different types of stresses that adversely impact different aspects of their being (psychological, social, cognitive and behavior). These stresses effects are different from one individual to another and hence it comes to reason that reactions towards them are also different, which is why some people are more capable of controlling their emotions compared to others and they can deal with the stressors in a positive manner. Hence, effective responses towards demands have key role in the successes of an individual in terms of his adaptation of and handling the stressors. Summarily speaking, different people respond different to stressors because each has his own distinct personal abilities and characteristics; for instance, while some individuals react positively (the type that are more successful in life), while others are faced with great difficulties in living and adapting towards stressors. In the context of higher studies, these stressors can come from incompatible university, incompatible educational approaches, ignorance of social activities, deficiency of person skills, among others (Varda, Retrum, \& Kuenzi, 2011; Sahebalzamani et al., 2013).

These problems underlying reason were examined by researchers over the past twenty years to find their resolution in the context of personal and social skills role in education (e.g. Low \& Nelson, 2005; Goleman, 
2000; Engelberg \& Sjoberg, 2004). Nevertheless, owing to the scarcity of studies that are focused on the issue in Saudi Arabia, this study attempts to extend literature and examine the issue in the context of Saudi university students - relevant issues include emotional and behavioral disturbance, social issues, psychological pressure, lack of leisure, average self-esteem level, self-injury, moderate level of social connectedness as discussed by prior studies (e.g. Abu-Zeid \& Abdel-Fattah, 2009; Abdel-Fattah et al., 2004; Al-Hattab, 2006; Al-Anazi \& Al-Shamli, 2011; Jdaitawi, Motawa, \& Al-Nabrawi, 2013). To this end, according to Low, Lomax, and Nelson (2005), the provision of training for personal and social skills considerably improves different academic aspects of the student-academic achievement, career excellence, personal health, well-being and development of leadership. As a consequence, personal and social skills training initiative would lead to enhanced student retention. Hence, in the present research, practical solutions are offered to educators in Saudi Arabia for optimum students' success in universities.

\subsection{Problem Statement}

Life skills education is among primary objectives behind the current education processes and is one of the many novel responsibilities that teachers undertake in this century. In this regard, international as well as regional institutions focus has been recently focused on the requirement to inculcate such skills and to include them in the study curricula and the training programs of teachers (Univesco, 1996; Alecso, 2004). More importantly, the university level of education is crucial in the lives of individuals as it is considered as the mainstream of trained leaders possessing theoretical and practical skills in all fields. Generally speaking, university students are faced with countless of stressors that could lead to significant issues that affect their psychological, social, cognitive and behavioral aspects. As mentioned, the effects of such stressors are different from one student to the next and hence, prior studies attempted to shed an insight into the source of pressures including low self-esteem, behavioral issues related to negative feeling towards peers, and low academic achievement, deficiency in emotional and social competency among others (Appleton, Christenson, \& Forlorn, 2008; Raver \& Kinder, 2002, Young, Storm, \& School, 1999).

In the context of Saudi Arabia, university students have been reported by studies to face certain issues in their academic lives (Abu-Zeid \& Abdel-Fattah, 2009; Abdel-Fattah et al., 2004). What little studies conducted in this field there are show that university students include behavioral and emotional disorders, social problems, psychological pressures, and unhappiness. All these issues result in regression in task achievement, ineffective study habits, failure and lack of goal setting and planning (Abo-Zeid et al., 2009; Abdel-Fattah et al., 2004; Al-Hattab, 2004; Al-Anazi \& Al-Shamble, 2011). Through a thorough literature review, a few studies of Western and Middle Eastern origin added to the development of specialized initiatives and programs that caters to the skills development among university students. The findings of the prior studies and a thorough literature review reveal that only a few studies have been dedicated to this particular field and as such, the present study contributes to literature by examining the development of over eight skills among Saudi university students.

\subsection{Significant of the Study}

In the context of education, the understanding of the students' success dynamics carried significant implications. Several researchers have therefore examined the importance of university education in a general sense (Mohammad et al., 2013; Chickering \& Reisser, 1993; Boulter, 2002; Baker \& Syrik, 1999). Suffice it to say that the identification and use of effective intervention in the refining and enhancing of first year students' academic and social skills are crucial. Several researchers have examined the required components to successful adaptation and the development of a positive learning environment. According to recent studies (Head, 2007; Goleman, 2001) university students' are impacted by both personal and social training programs and that emotional and social skills have a key role in the university students' successes. Nevertheless, mixed findings have been reported concerning the student's emotional and social skills and his success in the university (e.g. Abdallah et al., 2009; Naser \& Masrur, 2001; Bastian, Burns, \& Nettlebeck, 2005; Van-der Zee, Thijs, \& Schakel, 2002). This called for additional studies to explore students' success through the cognitive and non-cognitive factors affecting the same (Nelson \& Low, 2005; Kracher, 2009). Moreover, a universal need exists to conduct additional studies concerning the impact of personal and social training programs for the success of students (Jensen, Cohen, Rilea, Hannon, \& Howelles, 2007; Low, Lomax, Jackson, \& Nelson, 2004; Salami, 2010; Nelis, Quiodbach, Mikolajczak, \& Hansenne, 2009; Y. Lin, Lee, Hsu, \& S. Lin, 2011; Shah \& Thingujam, 2008). Hence, the present study contributes to literature by examining a training program involving personal and social skills in terms of its influence on student's university success.

\subsection{Objective of the Study}

This study attempts to determine the effect of a training program based on learning theories on the development 
of the university students' life skills during their study. Majority of studies in literature stressed on the lack of such initiatives for university students and hence, the current study investigates the impact of training program on the skills of university students. On the basis of the primary study aim, the following hypotheses are proposed to be tested;

H1: The training program enhances the self-confidence skills of Saudi male students in the experimental group compared to the controlled group.

$\mathrm{H} 2$ : The training program enhances the social interaction skills of Saudi male students in the experimental group compared to the controlled group.

H3: The training program enhances the self-awareness skills of Saudi male students in the experimental group compared to the controlled group.

H4: The training program enhances the problem solving skills of Saudi male students in the experimental group compared to the controlled group.

H5: The training program enhances the self-assertiveness skills of Saudi male students in the experimental group compared to the controlled group.

H6: The training program enhances the tolerance responsibility skills of Saudi male students in the experimental group compared to those in the controlled group.

H7: No significant statistical differences exist for the effect of the training program on the dependent variables based on the academic track.

\section{Study Method}

\subsection{Design and Sample}

This study is designed to conduct a pre- and post-test with experimental and control groups according to $2 \times 3$ factorial design. The sample constitutes 150 preparatory year university students randomly chosen on the basis of their inclination to take part in the programs. They were divided into experimental and controlled groups, with the study tracks being medical, engineering and science. Accordingly 75 students were assigned to the experimental group in a random manner and the other 75 to the controlled group according to their study tracks.

\subsection{Procedure}

In this study, a psycho-social personal skills training program was developed where students volunteered their contribution for a period of 4 days. The experimental group was provided 8 sessions of the program within two weeks while the controlled group was not given any training. The training program administration was overseen by four trainers and the training program was conducted via lectures, discussion and role-play. An overview of the training sessions is provided below;

The first session involved the description of the program through presentations, procedures, and the determination and relationship building among the members of the group. This is followed by the second session which involves self-awareness where members of the group are given time to understand themselves. The third session entailed self-confidence skills and the fourth one involved self-assertiveness skills. The students in the experimental group were trained in the fifth session on taking responsibility and on the sixth on interaction with others and objective determination of skills and targets planning. The seventh session included training for solving problem skills and lastly, the eighth session is when student practice, train and provide feedback after which the final evaluation takes place.

\subsection{Measurements}

Six scales that were used to measure items in the present study were translated into Arabic language by two language experts. The measurement of the six scales was scored with the help of a likert-scale and was validated in prior studies (e.g. Bradberry \& Greaves, 2004; Gok, 2012; Somiah, 2009; Awad, 2011; Helmreich \& Spence, 1983). The six scales are explained below;

1) Self-awareness scale: this scale was proposed by Bradberry and Greaves (2004) and it comprises 6 items measuring the student's self-awareness in the pre- and post-test. This scale was translated into Arabic and it has a reliability coefficient of 0.746 .

2) Interaction with others: this scale was created by Bradberry and Graves (2004) and it comprises 8 items measuring the way students interact with others in and outside of the university environment. This scale has a reliability coefficient of 0.822 in terms of internal consistency. 
3) Problem Solving Scale: this scale was proposed by Gok (2012) and it comprises 20 questions or items measuring students' problem solving skills. It has a reliability coefficient of 0.574 in terms of internal consistency.

4) Self-Confidence Scale: the self-confidence scale employed was the one developed by Somiah (2009), which consisted of 40 items that were divided into 20 positive and 20 negative items. The present study adopted the 20 former items without the latter as they consisted of other variables related to psychology. The scale's reliability coefficient was 0.973 in terms of internal consistency.

5) Tolerance of Responsibility Scale: this scale was developed and proposed by Awad (2011). The scale comprises 49 items that measure the student's responsibility tolerance. Only 20 items were employed in the present study according to the objectives. The scales reliability coefficient was reported to be 0.608 .

6) Assertiveness Scale: the development of this scale is attributed to Helmreich and Spence (1983) and it consists of 6 questions measuring the attitudes of students towards university work. It has a reliability coefficient of 0.548 in terms of internal consistency.

\section{Data Analysis}

Prior to conducting the hypotheses testing, the researcher ran the independent sample t-test to determine whether the two groups are statistically equivalent before the experiment was initiated. The dependent variables consisted of self-confidence, self-awareness, social interaction, self-assertiveness, problem solving and tolerance of responsibility.

The t-test was first ran on the first set of independent sample with the help of Levene's Test analysis to determine the differences between the two groups (experimental and controlled group) in terms of self-confidence, self-awareness, social interaction, self-assertiveness, problems solving and tolerance of responsibility based on the significance level of 0.5 . The results showed no significant differences between the two groups in terms of self-awareness pretest $(F=2.018, p=.158>.05)$, based on problem solving scale pretest $(F=1.933, p=.166>.05)$, based on social interaction pretest $(F=.123, p=.726>.05)$, based on self-assertiveness pretest $(F=1.206$, $p=.274>.05)$, and based on tolerance responsibility pretest $(F=.248, p=.620>.05)$. However, significant differences were noted between them based on self-confidence pretest $(F=154.015, p=.000>.05)$ as presented in the following Table 1 .

Table 1. Results of Levene's test for the research variables pretest

\begin{tabular}{lccccc}
\hline Variables & F-value & sig & $\mathrm{t}$ & $\mathrm{df} 2$ & Sig.(2-tailed) \\
\hline Self Confidence & 154.015 & .000 & -5.075 & 148 & .000 \\
Self-Awareness & 2.018 & .158 & .030 & 148 & .976 \\
Self-Assertiveness & 1.206 & .274 & .657 & 148 & .513 \\
Social Interaction & .123 & .726 & -1.285 & 148 & .201 \\
Problem Solving & 1.933 & .166 & .899 & 148 & .370 \\
Tolerance of Responsibility & .248 & .620 & -.652 & 148 & .515 \\
\hline
\end{tabular}

Moving on to the research hypotheses assessment, the researcher made use of descriptive analysis to determine the mean, value, minimum and maximum value for pretest and posttest of the dependent variables. In addition, inferential statistics analysis was employed for the assessment of research questions. Specifically, ANCOVA, ANOVA and MANOVA tests were conducted for the evaluation of the differences between means of the two groups both in pre- and post-test for the variables of self-confidence, self-awareness, social interaction, self-assertiveness, problem solving and tolerance of responsibility values. The ANOVA test was conducted for the comparison of means in posttest.

The pre- and post-test scores of dependent variables of the sample in terms of mean and standard deviation are presented in the statistics table. Based on the table, the experimental group participants showed an increase of mean scores after training for the variables as depicted in Table 2. Specifically, the experimental group showed a mean of pre-test score of $(\mathrm{M}=32.02, \mathrm{SD}=7.42)$, which was lower than the control group $(\mathrm{M}=41.60, \mathrm{SD}=14.55)$. After the test, the experimental group obtained higher mean scores $(\mathrm{M}=50.43, \mathrm{SD}=12.43)$ compared to their sample counterpart $(\mathrm{M}=35.20, \mathrm{SD}=3.51)$ and their mean scores for the variables of self-confidence improved 
with the test. With regards to self-awareness scores, the pre-test scores obtained by the experimental group was $(M=17.41, S D=2.52)$ that was higher compared to the controlled group $(M=17.40, S D=2.95)$. Similarly, after the test, the experimental group obtained the score of $(\mathrm{M}=17.37, \mathrm{SD}=2.71)$ while the controlled group obtained $(\mathrm{M}=17.26, \mathrm{SD}=2.71)$ indicating no enhancement of mean scores in self-awareness after training. In terms of social interaction, the experimental group obtained pre-test score of $(\mathrm{M}=22.89, \mathrm{SD}=3.58)$, which were less that that obtained by the controlled group ( $\mathrm{M}=23.65, \mathrm{SD}=3.66)$. Following the test, the result was the opposite in that the experimental group obtained higher scores $(M=23.34, S D=3.47)$ compared to the controlled group $(M=23.18$, $\mathrm{SD}=2.75$ ), indicating enhanced mean score for social interaction with training. Moving on self-assertiveness, the experimental group obtained mean scores of $(\mathrm{M}=14.96, \mathrm{SD}=2.19)$ before the test that was greater compared to that obtained by the controlled group $(\mathrm{M}=14.70, \mathrm{SD}=2.51)$. The results were similar after the test where the experimental group obtained higher mean scores $(\mathrm{M}=19.78, \mathrm{SD}=2.26)$ compared to the controlled group $(\mathrm{M}=35.20, \mathrm{SD}=3.51)$ indicating enhanced means score for this variable after training. In terms of problem solving, the experimental group obtained pre-test mean scores of $(\mathrm{M}=58.13, \mathrm{SD}=8.91)$ that were greater than that of their counterpart $(\mathrm{M}=56.98, \mathrm{SD}=6.51)$. The post-test mean scores had the same trend with the experimental group obtaining $(\mathrm{M}=62.84, \mathrm{SD}=5.48)$ and the controlled group obtaining $(\mathrm{M}=62.48, \mathrm{SD}=4.72)$ indicating that the former enhanced their mean score for problem solving after training. Lastly, with regards to tolerance responsibility, the experimental group obtained pre-test mean scores of $(\mathrm{M}=57.18, \mathrm{SD}=6.43)$ that were lower compared to the control group $(\mathrm{M}=57.86, \mathrm{SD}=6.34)$. However, the post-test scores were opposite with the experimental group obtaining $(\mathrm{M}=62.45, \mathrm{SD}=5.47)$ higher than the controlled group $(\mathrm{M}=60.26, \mathrm{SD}=4.88)$ and this indicates that the mean scores were enhanced after training.

Table 2. Summary statistics variables scores $(\mathrm{N}=43)$

\begin{tabular}{|c|c|c|c|}
\hline Variables & & Experimental Group & Control Group \\
\hline \multirow[t]{4}{*}{ Self Confidence } & Pretest & 32.02 & 41.60 \\
\hline & SD & 7.42 & 14.55 \\
\hline & Posttest & 50.93 & 35.20 \\
\hline & SD & 12.43 & 13.88 \\
\hline \multirow[t]{4}{*}{ Self-Awareness } & Pretest & 17.41 & 17.40 \\
\hline & $\mathrm{SD}$ & 2.52 & 2.95 \\
\hline & Posttest & 17.37 & 17.26 \\
\hline & $\mathrm{SD}$ & 2.71 & 2.71 \\
\hline \multirow[t]{4}{*}{ Self-Assertiveness } & Pretest & 14.96 & 14.70 \\
\hline & SD & 2.19 & 2.51 \\
\hline & Posttest & 19.78 & 17.94 \\
\hline & $\mathrm{SD}$ & 2.26 & 2.67 \\
\hline \multirow[t]{4}{*}{ Social Interaction } & Pretest & 22.89 & 23.65 \\
\hline & SD & 3.58 & 3.66 \\
\hline & Posttest & 23.34 & 23.81 \\
\hline & $\mathrm{SD}$ & 3.47 & 2.75 \\
\hline \multirow[t]{4}{*}{ Problem Solving } & Pretest & 58.13 & 56.98 \\
\hline & SD & 8.91 & 6.51 \\
\hline & Posttest & 62.84 & 62.48 \\
\hline & SD & 5.48 & 4.72 \\
\hline \multirow[t]{4}{*}{ Tolerance of Responsibility } & Pretest & 57.18 & 57.68 \\
\hline & $\mathrm{SD}$ & 6.43 & 6.34 \\
\hline & Posttest & 62.45 & 60.26 \\
\hline & SD & 5.47 & 4.88 \\
\hline
\end{tabular}


On explaining the results in terms of the hypothesized relationships, it is clear that in terms of hypothesis 1 ;

H1: The training program led to improving the self-confidence of Saudi male students in the experimental group. Upon considering the results of the dependent variables independently, ANCOVA analysis of variance was ran for post-test of self-confidence while controlling the covariance pretest-the result for the variable post-test indicates statistical significant difference $(\mathrm{p}=0.05, \mathrm{~F}=24.208, \mathrm{p}=.000,<0.05)$ as presented in Table 3 .

Table 3. Results of ANCOVA for between subject effect of the research variables: $P<.05$

\begin{tabular}{llccccc}
\hline Source & Dependent Variables Posttest & Type Sum of Square & df & Mean Square & F & P \\
\hline Group & Self-Confidence & 1678.320 & 1 & 1678.320 & 24.20 & .000 \\
& Self-Confidence Pretest & 15515.198 & 1 & 15515.198 & 223.78 & .000 \\
& Total Self-Confidence & 313200.00 & 150 & 15515.19 & 223.78 & .000 \\
\hline
\end{tabular}

Note. Significant $(\mathrm{p}<0.05)$.

As for the rest of the hypotheses;

H2-H6: The training program enhanced the Saudi male students' self-awareness, social awareness, social interaction, self-assertiveness, problem solving and tolerance of responsibility in the experimental group.

The five independent variables were run through MANOVA, with the independent variables present in experimental and controlled group. The first set of analysis results significant main effects for students' groups in terms of dependent variables. The box $\mathrm{M}$ test was employed to test the homogeneity of variance-covariance assumption that underplays MANOVA and the findings showed non-homogeneity. Added to this, a multivariate analysis highlighted statistical significant differences between the groups regarding dependent variables mean scores through the Pillais Trace criteria $F=(6.945, p=.000,<.0 .05)$. The results concerning the comparison between the dependent variables based on the influence of the independent variables showed significant differences between the two groups with $(F=20.685, p=.000, \boldsymbol{\eta}=.123 ; F=6.656, p=.011, \boldsymbol{\eta}=.034 ; F=.185, p=.001$, $\eta=.001)$ on self-assertiveness, tolerance of responsibility and problems solving respectively. The investigation that compared the independent variables influence on the dependent variables also showed no significant difference between the two in terms of self-awareness, social interaction and problem solving respectively $(F=.058, p=.810, \eta=.000 ; F=.098, p=.667, \eta=.001)$ as depicted in the Table 4 .

Table 4. Results of MANOVA for between subject effect of the research variables: $P<.05$

\begin{tabular}{llccccc}
\hline Source & Dependent Variables Posttest & Type Sum of Square & df & Mean Square & F & P \\
\hline Group & Self-Assertiveness & 126.960 & 1 & 126.960 & 20.685 & .000 \\
& Social Interaction & .960 & 1 & .960 & .098 & .755 \\
& Self-Awareness & .427 & 1 & .427 & .058 & .810 \\
& Problem Solving & 4.860 & 1 & 4.860 & .185 & .667 \\
& Tolerance of Responsibility & 179.307 & 1 & 179.307 & 6.656 & .011 \\
\hline Total & Self-Assertiveness & 1035.333 & 150 & & & \\
& Social Interaction & 1455.333 & 150 & & & \\
& Self-Awareness & 1090.640 & 150 & & & \\
& Problem Solving & 3885.660 & 150 & & & \\
& Tolerance of Responsibility & 4166.560 & 150 & & & \\
\hline
\end{tabular}

Note. Significant $(\mathrm{p}<0.05)$.

According to the obtained results, it can be concluded that partial significant difference exists in the mean total scores of dependent variables post-test between the two groups. Added to this, the mean total score of dependent variables in the post-test of the experimental group is evidently higher than that of the controlled group for majority of the variables under study. When the results for the dependent variables are considered separately, 
analysis of variance ANOVA is conducted, and the results for the variables that suggested statistical significance are self-assertiveness $(20.685, \mathrm{p}=.000<0.05)$; and tolerance of responsibility test only $(\mathrm{F}=6.656, \mathrm{p}=.011,<0.05)$; but the result of the self-awareness, social interaction and problem solving were not statistically significant at the $\mathrm{p}$ value of .05 as shown in Table 5 below.

Table 5. Results of ANOVA for between subject effect of the research variables: $P<.05$

\begin{tabular}{llccccc}
\hline Source & Dependent Variables Posttest & Type Sum of Square & df & Mean Square & F & P \\
\hline Group & Self-Assertiveness & 126.960 & 1 & 126.960 & 20.685 & .000 \\
& Social Interaction & .960 & 1 & .960 & .098 & .755 \\
& Self-Awareness & .427 & 1 & .427 & .058 & .810 \\
& Problem Solving & 4.860 & 1 & 4.860 & .185 & .667 \\
& Tolerance of Responsibility & 179.307 & 1 & 179.307 & 6.656 & .011 \\
\hline Total & Self-Assertiveness & 1035.333 & 150 & & & \\
& Social Interaction & 1455.333 & 150 & & & \\
& Self-Awareness & 1090.640 & 150 & & & \\
& Problem Solving & 3885.660 & 150 & & & \\
& Tolerance of Responsibility & 4166.560 & 150 & & & \\
\hline
\end{tabular}

Note. Significant $(\mathrm{p}<0.05)$.

As for final hypothesis (H7);

H7: No significant statistical differences were found for the training program's effect on the dependent variables according to the academic tracks. MANCOVA was run on the six dependent variables of self-confidence, self-awareness, social interaction, self-assertiveness, problems solving and tolerance of responsibility. The study tracks involved included medicine, engineering and science. The first analysis set produced significant main effects for students' track with dependent variables. The box M test was employed to test the homogeneity of variance-covariance assumption that underplays MANCOVA and according to the results, homogeneity was not satisfied.

According to the multivariate test conducted, there exist differences among students tracks based on dependent variables cores obtained through Pillais Trace criteria $(F=4.288, p=.000,<.0 .05)$. The investigation results compared the independent variables influence on the dependent ones in terms of study tracks and significant differences were found among the three tacks; specifically, for medicine, self-awareness and self-assertiveness results were $(F=5.691, p=.004, \eta=.075 ; F=16.776, p=.000, \eta=.192)$ respectively. No significant differences were found among the tracks in terms of self-confidence, social interaction, problem solving and tolerance of responsibility as evidenced by the results $(F=.246, p=.783, \eta=.003 ; F=2.769, p=.066, \eta=.038 ; F=.633, p=.533$, $\eta=.009 ; F=1.830, p=.164, \eta=.025)$ presented in Table 6. 
Table 6. Results of MANCOVA for between subject effect of the research variables: $P<.05$

\begin{tabular}{llccccc}
\hline Source & Dependent Variables Posttest & Type Sum of Square & df & Mean Square & F & P \\
\hline Group & Self-Confidence & 73.866 & 2 & 18.933 & .246 & .003 \\
& Self-Assertiveness & 175.345 & 2 & 87.672 & 16.776 & .192 \\
& Social Interaction & 41.260 & 2 & 20.630 & 2.769 & .066 \\
& Self-Awareness & 53.400 & 2 & 26.700 & 5.691 & .004 \\
& Problem Solving & 31.697 & 2 & 15.849 & .633 & .533 \\
& Tolerance of Responsibility & 89.493 & 2 & 44.746 & 1.830 & .164 \\
\hline Total & Self-Confidence & 34989.33 & 149 & & & \\
& Self-Assertiveness & 54428.00 & 149 & & & \\
& Social Interaction & 82656.00 & 149 & & & \\
& Self-Awareness & 46088.00 & 149 & & & \\
& Problem Solving & 592827.0 & 149 & & & \\
& Tolerance of Responsibility & 568924.0 & 149 & & & \\
\hline
\end{tabular}

\section{Discussion}

According to Reason (2009), obtaining a college degree holds an important area of study in higher education field. Universities are facing the challenge of efficiency generating students who are critical thinkers, relationship prone, and those who can adopt learn and deal with independence (Astin, 1993; Low \& Nelson, 2005). An increasing proportion of literature evidenced that a training program could enhance the students' success in universities in terms of personal skills, social skills, social behavior and academic success (Meyer, Fletcher \& Parker, 2004; Parker et al., 2005). However, evidence on the potential use of training in enhancing social and academic success of university students is still scarce (Low \& Nelson, 2003; Li, Wright, Rukavina, \& Pickering, 2008). Hence, the present study attempted to determine whether training program sessions could improve the self-confidence, self-awareness, self-assertiveness, social interaction, problem-solving and tolerance responsibility skills among Saudi university students.

Consistent with the first hypothesis, the findings showed the training course to improve the self-confidence of the students-this finding is aligned with that of Asting (1993), Lotkowski, Robbins, and Noeth (2004). This can be attributed to the fact that students are involved in some extracurricular activities that may contribute positively to their interpersonal relationship with their peers and instructors and that could motivate their positive development. Training also significant enhanced the self-assertiveness of the students and their tolerance for responsibility. It can therefore be concluded that the training tasks helped in enhancing the students' ability to be responsible in completing their tasks successfully and taking active part in the group via training. This may also develop their character as they have to relate to their peers while enhancing their skills.

On a similar finding, other researchers including Escarti, Gutierrez, Pascual, and Liopis (2010), Hellison (1985, 2003) and Margolis and McCabe (2006) also reported the same findings indicating that when adolescents take part in extracurricular activities, opportunities for interaction with their peers are developed which provides them the chance to develop friendships and social confidence (Wilson, 2009). In addition, participation of students may also indicate maturity and self-affirming actions as those who took part in a same-caliber study by Wilson (2009) appeared to have developed a sense of commitment and obligation (Wilson, 2009). To conclude, those participating in extracurricular activities displayed greater self-perception that those who did not (Daley \& Leahy, 2003).

The second set of results regarding self-awareness, problem solving and social interaction showed no statistical difference in improvement among students. This may be attributed to the content of the training sessions, which were ineffective in enhancing the level of skills. Moreover, owing to their complexity, they may not have been suitable for the students and hence, the non-statistical significance. The results contrasted with those reported by L. Snyder and M. Snyder (2008).

As for the third set of analysis results concerning the different impact of the training programs among the students' self-confidence, self-awareness, self-assertiveness, social interaction, problem solving and tolerance of 
responsibility according to their study tracks showed significant differences for both self-awareness and self-assertiveness skills among medicine students, with the exception of other skills. This may be explained by the fact that students of medicine are highly aware of themselves which may lead to the affirmation of their behavior. Added to this, students in medicine are often challenged in their field and require more awareness both in and out their classes.

\subsection{Limitations and Recommendations}

The evaluation of students' success in the university level has recently been increasingly focused on. On the basis of evidence garnered from reports, a large proportion of university students drop-out of universities prior to obtaining their degrees. Hence, prior studies urged for the creation of training programs to resolve the issue (e.g. Low \& Nelson, 2005; Li, Wright, Rukavina, \& Pickering, 2008). In response to this urging, the present study attempted to create a training program to improve the students' skills and to bring about the success of students in terms of social and academic skills at the university (i.e. enhancing self-awareness, self-confidence, self-assertiveness social interaction, problem solving and tolerance of responsibility. However, like other studies, the present one has some limitations. First, the sample of this study was obtained via purposive sampling and it comprised of first year university students. This type of sampling limits the ability of results generalization into the more general population (Fisher et al., 2002). Second, quantitative data was obtained with the help of self-report measures giving the participants considerable opportunity to manipulate their answers to get over the tests quickly and to satisfy the researcher-there may be voluntary or involuntary answer choices that contradicts actual experience (Creswell, 1994). Future studies may resolve this limitation by using qualitative methods to highlight the actual perception of students of their university success. Lastly, the training program was employed for a short time and hence may confine generalization and as such, this study recommends future studies to allocate more time for accurate results.

\section{Acknowledgments}

This work was supported by Deanship of Scientific Research, University of Dammam, under award number (2014288).

\section{References}

Abdallah, M. C., Elias, H., Mahyuddin, R., \& Uli, J. (2009). Adjustment amongst first year students in a Malaysian university. European Journal of Social Sciences, 8(3), 496-505. Retrieved September 1, 2009, from http://www.eurojournals.com/ejss_8_3_13.pdf

Abdel-Fattah, M., Asal, A., Al-Asmary, S., Al-Helali, N., Al-Jabban, T., \& Arafa, M. (2004). Emotional and Behavioral Problems Among Male Saudi School Children and Adolescents Prevalence and Risk Factors. German Journal of Psychiatry.

Abu-Zeid, A., Hifnawy, T., \& Abdel-Fattah, M. (2009). Health Habits and Behaviour of Adolescent School Children, Taif, Saudi Arabia. Eastern Mediterranean Health Journal, 15(6), 1525-1534.

Al-anazi, H., \& Al-Shamli, A. (2011). Sensation Seeking and Delinquency among Saudi Adolescents. European Journal of Social Sciences, 21(2), 265-286.

Al-Hattab, A. (2006). Self Esteem and Writing Achievement of Saudi EFL Students in Secondary Schools (Unpublished master thesis). Taibah University, Saudi Arabia.

Appleton, J., Christenson, S., \& Furlong, M. (2008). Student engagement with school: Critical conceptual and methodological issues of the construct. Psychology in the Schools, 45(5), 369-386. http://dx.doi.org/10.1002/pits.20303

Astin, A. W. (1993a). What Matters in College. Liberal Education, 79(4), 4-15.

Baker, R. W., \& Siryk, B. (1999). Student adaptation to college questionnaire manual. Los Angeles: Western Psychological Services.

Bastian, V. A., Burns, N. R., \& Nettelbeck, T. (2005). Emotional intelligence predicts life skills, but not as well as personality and cognitive abilities. Personality and individual differences, 39, 1135-1145.

Boulter, L. T. (2002). Self-concept as predictor of college freshman academic adjustment. College Student Journal, 36(4), 35-41.

Chickering, A., \& Reisser. L. (1993). Education and identity (2nd ed.). San Francisco: Jossy Bass.

Creswell, J. W. (1994). Research design qualitative \& quantitative approaches. London: SAGE Publications. 
Daley, A., \& Leahy, J. (2003). Self-perceptions and participation in extracurricular physical activities. The Physical Educator, 60(2), 13-19.

Engelberg, E., \& Sjoberg, L. (2004). Emotional intelligence, affect intensity, and social adjustment. Personality and Individual Differences, 37, 533-542.

Escartí, A., Pascual, C., \& Gutiérrez, M. (2005). Responsabilidad personal y social a través de la educaciónfisica y el deporte. Barcelona: Graó.

Fisher, A. A., Foreit, J. R., Laing, J., Stoeckel, J., \& Townsend, J. (2002). Designing HIV/AIDS intervention studies: An operations research handbook. The Population Council Inc. Retrieved July 23, 2009, from http://www.popcouncil.org/pdfs/horizons/orhivaidshndbk.pdf

Goleman, D. (2000). Emotional intelligence. Issue in Paradigm Building. Inc

Goleman, D. (2001). An ei-based theory of performance. In C. Cherniss, \& D. Goleman (Eds.), The emotional intelligence workplace: How to select for, measure, and improve emotional intelligence in individual, groups, and organization. San Francisco: Jossy-Bass.

Head, T. L. (2007). Examining the experience of students enrolled in small community colleges by time of enrollment (Unpublished Doctoral Dissertation). University of Texas of Austin, Texas, USA.

Jdaitawi, M., Motawa, A., \& Al-Nabrawi, I. (2013). Analysis of Adolescent period in Saudi Arabia: Social connectedness. Paper accepted at 7th International Technology, Education and Development Conference (INTED2013/4th-6th March), Valencia, Spain.

Jensen, S., Cohen, C., Rilea, S., Hannon, R., \& Howells, G. (2007). Emotional intelligence: A literature review. University of the Pacific. Retrieved July 13, 2009, from http://web.pacific.edu/Documents/library/acrobat/EI\%20Lit\%20Review\%202007\%20Final.pdf

Kracher, C. (2009). Academic and non-academic factors associated with retention of undergraduate college students (Unpublished Doctoral Dissertation). Lynn University.

Li, W., Wright, P., Rukavina P. B., \& Pickering, M. (2008). Measuring students' perceptions of personal and social responsibility and the relationship to intrinsic motivation in urban physical education. Journal of Teaching in Physical Education, 27, 167-178.

Lin, Y., Lee, T., Hsu, S., \& Lin, S. (2011). What causes the emotional intelligence suffered by students at universities and colleges of technology? World Transactions on Engineering and Technology Education, 9(2), 102-108.

Lotkowski, V., Robbins, S., \& Noeth, R. (2004). The role of academic and non-academic factors in improving college retention. ACT Information for life Transitions. Retrieved 3, June, 2014, from http://www.act.org/research/policymakers/pdf/college_retention.pdf

Low, G., \& Nelson, D. (2005). Emotional intelligence: The role of transformation learning in academic excellence. Texas Study of Secondary Education, 2, 41-44. Retrieved September 10, 2014, from http://www.tamuk.edu/edu/kwei000/research/articles/article_files/ei_transformativelearning.pdf

Low, G., Lomax, A., Jackson, M., \& Nelson, D. (2004). Emotional intelligence: A new student development model. A Paper presented at the National Conference of the American College Personal Association in Philadelphia Pennsylvania.

Margolis, H., \& McCabe, P. (2006). Improving self-efficacy and motivation: What to do, what to say. Intervention in School and Clinic, 41, 218-227.

Meyer, B., Fletcher, T., \& Parker, S. (2004). Enhancing emotional intelligence in the health care environment: An exploratory study. Health Care Manager, 23(3), 225-234.

Nadim, P. (1995). An investigation of assertive behavior in visually impaired young adults and an experimental groups study with visually impaired adolescents (Unpublished master's thesis). Marmara University, İstanbul.

Nasar, M., \& Masrur, R. (2010). An exploration of emotional intelligence of the students of IIUI in relation to gender, age and academic achievement. Bulletin of Education and Research, 32(1), 37-51.

Nelis, D., Quoidbach, J., Mikolajczak, M., \& Hansenne, M. (2009). Increasing emotional intelligence: (How) is it possible? Personality and Individual Differences, 47(1), 36-41.

Parker, J. D., Duffy, J. M., Wood, L. M., Bond, B. J., \& Hogan, M. J. (2005). Academic achievement and 
emotional intelligence: Predicting the successful transition from high school to university. Journal of the First-Year Experience, 17(1), 1-12.

Raver, C. C., \& Knitze, J. (2002). Ready to Enter: What Research Tells Policymakers About Strategies to Promote Social and Emotional School Readiness Among Three-and Four-Year-Old Children Policy Paper. No. 3 Promoting the Emotional Well-Being of Children and Families National Center for Children in Poverty.

Reason, R. (2009). An examination of persistence research through the lens of a comprehensive conceptual framework. Journal of College Student Development, 50(6), 659-682. http://dx.doi.org/10.1353/csd.0.0098.

Sahebalzamani, M., Moraveji, M., Faraani, M., \& Feizi, F. (2013). Investigation the effect of life skills training on students emotional reactions. Journal of Applied Environmental and Biological Sciences, 3(9), 134-137. Retrieved 13 June, 2014, from http://txtpaper.com/Old\%20Version/pdf/JAEBS/J.\%20Appl.\%20Environ.\% 20Biol.\%20Sci.,\%203(9)134-137,\%202013.pdf

Salami, S. D. (2010). Emotional intelligence, self-efficacy, psychological well-being and students attitudes: Implication for quality education. European Journal of Educational Studies, 2(3), 247-257.

Shah, M., \& Thingujan, N. (2008). Perceived emotional intelligence and ways of coping among students. Journal of the Indian Academy of Applied Psychology, 34(1), 83-91.

Snyder, L., \& Snyder, M. (2008). Teaching critical thinking and problem solving skills. The Delta Pi Epsilon Journal, 2, 90-99.

Tinto, V. (1998). Colleges as communities: Taking research on student persistence seriously. Review of Higher Education, 21(2), 167-177.

Van der Zee, K., Thijs, M., \& Schakel, L. (2002). The relationship of emotional intelligence with academic intelligence and the big five. European Journal of Personality, 16, 103-125.

Varda, D., Retrum, J., \& Juenzi, K. (2011). The influence of teaching methodology on student social interaction.Journal of Public Affairs Education, 18(4), 633-660. Retrieved 27 May, 2014, from http://www.naspaa.org/jpaemessenger/article/vol18-4/03_vardaretrumkuenzi.pdf

Wilson, N. (2009). Impact of extracurricular activities on students (Unpublished master thesis). University of Wisconsin-Stout.

\section{Copyrights}

Copyright for this article is retained by the author(s), with first publication rights granted to the journal.

This is an open-access article distributed under the terms and conditions of the Creative Commons Attribution license (http://creativecommons.org/licenses/by/3.0/). 